\section{Violência institucional, autoridade médica e poder nas maternidades sob a ótica dos profissionais de saúde}

\author{
Institutional violence, medical authority, and \\ power relations in maternity hospitals from the \\ perspective of health workers
}

\author{
Violencia institucional, autoridad y poder en la \\ atención maternal desde la perspectiva de los \\ profesionales sanitarios
}

Janaina Marques de Aguiar 1 Ana Flávia Pires Lucas d'Oliveira 1 Lilia Blima Schraiber 1

\author{
${ }^{1}$ Faculdade de Medicina, \\ Universidade de São Paulo, \\ São Paulo \\ Correspondência \\ J. M. Aguiar \\ Departamento de Medicina \\ Preventina, Faculdade de \\ Medicina, Universidade de \\ São Paulo. \\ Av. Dr. Arnaldo 455, sala 2170 \\ São Paulo, SP 01246-000, \\ Brasil. \\ jamaragui@gmail.com
}

\begin{abstract}
The current article discusses institutional violence in maternity hospitals from the health workers' perspective, based on data from a study in the city of São Paulo, Brazil. Eighteen health workers from the public and private sectors were interviewed, including obstetricians, nurses, and nurse technicians. A semi-structured interview was used with questions on professional experience and the definition of violence. The analysis revealed that these health workers acknowledged the existence of discriminatory and disrespectful practices against women during prenatal care, childbirth, and the postpartum. Examples of such practices cited by interviewees included the use of pejorative slang as a form of "humor", threats, reprimands, and negligence in the management of pain. Such practices are not generally viewed by health workers as violent, but rather as the exercise of professional authority in what is considered a "difficult" context. The institutional violence is thus trivialized, disguised as purportedly good practice (i.e., "for the patient's own good"), and rendered invisible in the daily routine of care provided by maternity services.
\end{abstract}

Violence Against Women; Maternal Health Services; Women

\section{Resumo}

O presente artigo discute a violência institucional em maternidades sob a ótica de profissionais de saúde, com base nos dados de uma pesquisa sobre o tema na cidade de São Paulo, Brasil. Para tanto, foram entrevistados 18 profissionais de saúde atuantes nas redes pública e privada, dentre médicos obstetras, enfermeiras e técnicas em enfermagem. Foi utilizado um roteiro semiestruturado com questões sobre a experiência profissional e o conceito de violência. A análise revelou o reconhecimento desses profissionais de práticas discriminatórias e desrespeitosas no cotidiano da assistência a mulheres gestantes, parturientes e puérperas. São exemplos citados dessas práticas o uso de jargões pejorativos como forma de humor, ameaças, reprimendas e negligência no manejo da dor. Essas práticas não são geralmente percebidas pelos profissionais como violentas, mas sim como um exercício de autoridade em um contexto considerado "difícil". Tal contexto revela a banalização da violência institucional que travestida de boa prática, porque seria para o bem da paciente, acaba invisibilizada no cotidiano da assistência.

Violência Contra a Mulher; Serviços de Saúde Materna; Mulheres 


\section{Introdução}

A violência institucional em maternidades públicas tem sido apontada em alguns estudos como resultado da própria precariedade do sistema de saúde 1,2,3 e entendida como ligada à falta de investimentos no setor. Em outros estudos, a explicação de sua ocorrência inclui a conduta pessoal de desrespeito dos profissionais às pacientes 4,5,6,7. Embora relações desiguais de poder marquem a interação médico/paciente em geral, neste caso, a nosso ver, a desigualdade pode ser transformada em violência de gênero, cuja ocorrência está relacionada à conjugação de serem mulheres além de pacientes, anulando-as como sujeitos de direitos, particularmente os direitos sexuais e reprodutivos. Essa forma de violência de gênero pode estar constituída de atos de negligência, maus-tratos físicos e verbais, e violência sexual 4,5,6,7,8,9. Entendemos gênero como um lócus de exercício de poder instituído por meio de uma ideologia dominante com normas que determinam papéis sociais para homens e mulheres pautados na diferença sexual 10 .

O tema traz para a reflexão o próprio exercício do poder e da autoridade médicos que se estende em diferentes medidas a todos os profissionais de saúde envolvidos na assistência às mulheres, bem como a todos os demais usuários de serviços de saúde. Diversas esferas dos setores público e privado têm se mobilizado em torno dessa questão realizando investigações e debates. A própria política de humanização da assistência hospitalar e o Programa de Humanização do Parto e Nascimento do Ministério da Saúde 11 são exemplos de respostas à insatisfação dos usuários com um tratamento denunciado como desrespeitoso, violento e uso indiscriminado de tecnologias que resultam em altas taxas de cesarianas e dor iatrogênica 12 . De acordo com Deslandes (p. 9) 13, "resgatar a humanidade do atendimento, numa primeira aproximação, é ir contra a violência, já que esta representa a antítese do diálogo, a negação do 'outro' em sua humanidade".

O presente artigo apresenta e discute dados de uma pesquisa realizada com profissionais de saúde sobre a violência institucional em maternidades públicas, analisada à luz das relações entre o poder e a autoridade médicos e as relações de gênero.

\section{Violência, autoridade médica e poder: considerações teóricas}

A fim de definir o que consideramos como violência em maternidades, adotamos o conceito proposto por Chauí 14 sobre violência, entendida como a transformação de uma diferença em desigualdade numa relação hierárquica com o objetivo de explorar, dominar e oprimir o outro que é tomado como objeto de ação, tendo sua autonomia, subjetividade, comunicação e ação livres impedidas ou anuladas.

Nesse sentido, buscamos compreender os mecanismos pelos quais o poder é exercido nessas instituições e o que torna possível o exercício de uma assistência violenta em um contexto em que se espera o cuidado à mulher e ao bebê. Tomamos adicionalmente dois outros autores que também discutem, ainda que por aproximações diversas, a relação entre violência e poder: Arendt 15 e Foucault 16.

Diante de relatos de maus-tratos vividos pelas pacientes se poderia pensar que a violência seria um uso extremo do poder por parte dos profissionais, sendo violência e poder dois aspectos de um mesmo fenômeno com diferenças apenas quantitativas. A nosso juízo, a violência não é um uso excessivo ou exagerado do poder, uma expressão de "mais do mesmo" poder. Ao contrário, a violência constitui uma ausência de poder ao ser exercício de uma autoridade não legitimada. Assim, trata-se de um "não poder", pela maior autoridade que se faz com recurso à força física ou a outros recursos de violação de direitos, nas relações entre sujeitos sociais 15 .

Em nosso caso, teremos profissionais e usuários de serviços cujas legítimas autoridades desiguais, por exemplo, em termos do saber e da prática da medicina na relação do médico com seu paciente, são burladas. A violência muda o caráter desse poder anteriormente exercido ao desrespeitar o domínio legitimamente conquistado da autoridade maior, quando o médico extrapola para além do plano técnico-científico seu juízo profissional, resvalando para o plano da moral com julgamentos de valor sobre o outro 17 .

De acordo com Arendt 15, o poder emerge da ação e da fala em concerto de um grupo, e sua existência depende da comunicação neste grupo. Ele é, portanto, um fim em si mesmo, diferentemente da violência, cujo caráter instrumental faz com que o poder seja utilizado para alcançar determinado fim. Tal uso instrumental se faz, enquanto violência, por sobre o outro da relação e não em interação com este outro. Para a autora, a violência impede o poder, porque obstaculiza a sua fonte última de geração: a comunicação livre entre as pessoas.

Foucault 16 , por sua vez, considera que o poder é uma forma de ação sobre a ação dos outros e sustenta que o seu exercício se dá por meio das inter-relações. Segundo o autor, para que uma relação de poder exista é indispensável que o su- 
jeito sobre cuja ação o poder se exerce seja reconhecido como um sujeito de ação, e que, desta forma, diante da relação de poder haja sempre um campo de possibilidades para ações, respostas, reações, efeitos e invenções. A violência implica a própria anulação das possibilidades de ação, utilizando-se da força, da coação ou mesmo da destruição como formas de ação.

No âmbito das práticas de saúde, o poder é exercido numa relação hierárquica por definição, a relação profissional/paciente. No topo dessa hierarquia está o médico como aquele que detém a maior autoridade técnico-científica sobre o corpo. Autoridade que legitimamente é estendida somente a esse plano - técnico-científico uma vez que no plano moral, ambos os sujeitos, profissional e paciente, encontram-se em situação de igualdade 17.

De acordo com Starr 18 essa autoridade técnico-científica é a fonte do poder médico, pautada em dois pilares: a legitimidade científica de seus conhecimentos e a dependência dos indivíduos em relação a estes conhecimentos, uma vez que a saúde tem um valor inequívoco de importância para todos e a não obediência à autoridade médica pode resultar em danos (antecipáveis) para a saúde do paciente.

Tanto para Starr ${ }^{18}$ quanto para Arendt $15 \mathrm{a}$ autoridade é uma faculdade que suscita a confiança no outro e a obediência voluntária porque pressupõe a liberdade dos sujeitos envolvidos. Quando a confiança gerada no consenso de um grupo sobre a legitimidade daquela autoridade rompe e há o uso da violência para manter a obediência (que não é mais voluntária) a base de sustentação da autoridade e do poder fica fragilizada.

A violência institucional em maternidades no atual modelo da medicina tecnológica se dá em um contexto de "crise de confiança" ${ }^{19}$, caracterizado principalmente por uma valorização do uso da tecnologia em detrimento das interações humanas, ou seja, os recursos tecnológicos, ao invés de meios, passam a ser tomados como fins em si mesmos. De acordo com Schraiber 19, tal mudança acaba resultando em uma série de rupturas interativas em diversos planos, tanto entre profissional de saúde e paciente, conduzindo a uma despersonalização dos cuidados em saúde, com fragilização dos vínculos na relação entre os mesmos, quanto entre profissionais de saúde e destes com o seu próprio saber - o que a autora denomina de "anulação da reflexividade em sua prática”, ou seja, a não reflexão sobre sua atuação na aplicação do saber técnico-científico para cada caso. Essa mudança no caráter das relações imputa à medicina moderna uma dupla perda: como valor ético humano e como necessidade técnica 19.
A perda da ética, que significa para a autora interesse por e cuidado para com o outro, como sujeito inteiro e não somente como corpo biomédico, conduz ao fracasso técnico e prático, podendo engendrar a violência (transformando sujeito em objeto), em função da dependência e legitimidade do saber e prática envolvidos. Essa erosão da qualidade ética das interações entre profissionais e pacientes é, em grande parte, a responsável pela crise de confiança.

É no campo das relações entre profissionais e pacientes que encontramos as situações de violência mais difíceis de serem percebidas como tal pelos sujeitos envolvidos, ainda que impliquem de forma bastante clara a anulação da autonomia e a discriminação por diferença de classe, raça ou gênero. Essas formas estão frequentemente presentes em falas grosseiras, desrespeitosas e discriminatórias para com as pacientes e em desatenção quanto às suas necessidades de analgesia e uso apropriado de tecnologia, podendo ser expressadas também por agressões físicas ou sexuais explícitas.

Buscando compreender melhor essas situações, desenvolvemos uma pesquisa qualitativa com usuárias de maternidades públicas e profissionais do Município de São Paulo sobre a violência institucional em maternidades. No presente artigo abordaremos os dados relativos aos profissionais.

\section{Material e método}

Foram realizadas, de março a setembro de 2008, 21 entrevistas semiestruturadas com puérperas e 18 com profissionais de saúde (10 obstetras, 5 enfermeiras e 3 técnicas de enfermagem). A captação dos profissionais para as entrevistas se deu por intermédio de indicação interpessoal, conhecida como "bola de neve", na qual profissionais trabalhadores de maternidades da região de São Paulo indicaram colegas e assim sucessivamente, formando uma ou várias redes de indicações. O primeiro entrevistado foi indicado pela orientadora do estudo. Tivemos um número baixo de recusas, todas justificadas pela falta de disponibilidade de tempo.

Uma vez que os profissionais trabalhavam tanto em maternidades públicas como privadas, as experiências relatadas referem-se ao conjunto de maternidades onde exerciam suas atividades profissionais, compreendendo serviços universitários e vários hospitais credenciados como Amigo da Criança. Enfocaremos neste texto especialmente as falas referentes às maternidades públicas. As maternidades referidas não se diferenciam como as de piores condições de trabalho 
ou recursos técnicos e materiais, fazendo parte do grupo estudado alguns serviços reconhecidos como de excelência.

As entrevistas foram realizadas em locais de escolha dos profissionais, nunca nos hospitais referidos. A via de contato por indicação de um colega facilitou tanto a abordagem da pesquisadora para o convite da entrevista quanto a aceitação do profissional.

O critério para o número de entrevistas foi a saturação do tema. O roteiro investigou as experiências profissionais sobre o objeto do estudo, bem como concepções e valores morais acerca do mesmo. As entrevistas foram gravadas e transcritas concomitantemente, permitindo a leitura paralela do material à medida que era produzido, o que possibilitou o aprofundamento de temas que surgiam do material empírico e se destacavam como categorias para uma análise temática. Posteriormente, realizamos leituras detalhadas de cada entrevista e do conjunto de respostas agrupadas por eixos temáticos (cuidado, maustratos, estereótipos de classe e gênero, autoridade médica, causas e possibilidades de prevenção da violência institucional), possibilitando o reconhecimento do perfil particular de cada sujeito entrevistado e a articulação dos eixos com categorias analíticas mais abrangentes (gênero, violência e poder).

A pesquisa foi aprovada pelos Comitês de Ética em Pesquisa da instituição acadêmica a qual estava vinculada e da Secretaria de Saúde do Município de São Paulo, respeitando os princípios estabelecidos pelos respectivos comitês para pesquisas com seres humanos, de acordo com a Declaração de Helsinki (2000) da Associação Médica Mundial. Todos os entrevistados assinaram o Termo de Consentimento Livre e Esclarecido.

\section{Perfil dos entrevistados}

A idade dos entrevistados variou entre 26 e 53 anos. O tempo de profissão dos obstetras variou entre 7 e 30 anos. Seis deles tinham mais de 15 anos de carreira. Dentre as enfermeiras e técnicas de enfermagem mais da metade exercia a profissão há mais de 9 anos.

Vários entrevistados tinham relação com serviços de ensino, sendo profissionais reconhecidos como tendo boa formação e qualidade na assistência. Todas as enfermeiras possuíam especialização em obstetrícia e todas as técnicas atuavam no centro obstétrico e centro cirúrgico, prestando assistência à paciente e/ou ao recémnascido nos cuidados imediatos.

A maioria trabalhava em mais de uma instituição (públicas e privadas). A carga horária fixa relatada pelos obstetras foi de no mínimo 40 ho- ras semanais (incluindo plantões de fim de semana) e no máximo 60, sem contar o tempo em que atendiam em consultório particular. Dentre as enfermeiras e técnicas a carga horária variou entre 40 e 72 horas semanais de trabalho.

No que se refere à divisão por sexo, apenas 6 homens foram entrevistados (todos obstetras), as demais mulheres eram 4 obstetras, 5 enfermeiras e 3 técnicas. Essa divisão não foi intencional e reflete, de alguma forma, a realidade dos hospitais, onde o corpo de enfermagem é composto majoritariamente por mulheres. No entanto, não houve diferenças, relevantes para a análise, nos relatos de profissionais homens e mulheres em relação à sua prática profissional e suas concepções de violência.

\section{Os tênues limites entre autoridade e violência}

A sobrecarga de demandas, as condições estruturais e a precariedade de recursos materiais e humanos foram apontadas pelos entrevistados como dificuldades enfrentadas cotidianamente. As consequências dessas dificuldades vão desde a falta de anestesistas de plantão para realização de analgesias de parto até a proibição de acompanhantes homens na sala de pré-parto, sob a alegação de falta de espaço físico que garanta a privacidade para as demais pacientes.

Também foram apontadas dificuldades na relação com as pacientes. Alguns profissionais revelaram uma imagem das usuárias do serviço público como ignorantes, com dificuldades de compreensão do que é dito e com uma sexualidade difícil de ser controlada (por terem muitos filhos e ainda muito jovens). A agressividade que as pacientes dirigem aos profissionais, vista por estes como um tipo de violência institucional, também encontra na esfera do caráter pessoal e no preconceito de classe sua justificativa - a paciente é rude, "grosseirona” por "natureza”, por não saber lidar com os outros, ou pelo grupo social ao qual pertence - gente pobre e ignorante.

Atitudes e comportamentos das pacientes e dos profissionais estão sujeitos a serem interpretados equivocadamente, por ambas as partes 20 . O resultado acaba sendo uma comunicação truncada de reinterpretação de falas e sentimentos que pode fazer com que a paciente colabore pouco com a equipe justamente por não entender o que esperam dela.

Nesse sentido, a agressividade das pacientes é associada por profissionais também a uma banalização da violência no meio social ao qual pertencem ou a uma reação defensiva por parte desta pelo medo de sofrer maus-tratos. Todos os profissionais confirmaram que as pacientes já 
chegam ao serviço público com medo de serem maltratadas, porque já o foram anteriormente ou porque foram avisadas desta possibilidade pelas pessoas de sua rede social.

"Geralmente os casos mais difíceis acabam sendo as pacientes que passaram por vários hospitais públicos, então elas acabam chegando com pedras na mão" (Obstetra 8).

"Olha, tanto que se você perguntar pra uma mulher tem uma coisa assim: 'Se eu gritar a enfermeira judia de mim'. Todas falam" (Obstetra 9).

A maioria dos entrevistados ressaltou como mais difíceis as pacientes não colaborativas ou escandalosas. A "não colaborativa" seria aquela que fecha a perna; não escuta o profissional; não faz força percebida como efetiva; "atrapalha" o trabalho do profissional; chega "despreparada" para o parto (geralmente atribuído a um prénatal inadequado); dispersa (que não está focada no parto); não entende o que o profissional fala (porque teria baixa escolaridade ou pela própria "fisiologia" do parto que a deixa "fora de si"); ou ainda, aquela paciente com um perfil mais agressivo, que é rude no trato, que recusa ou dificulta o exame e de difícil condução do trabalho de parto.

A “escandalosa”, consoante com a definição dada pela maioria das puérperas entrevistadas 21 , é a paciente "histérica"; descontrolada; que não fica quieta (não para na mesa, pula da cadeira, fica de pé, grita, dá murro, chute, levanta o quadril, tira a perna da perneira); que faz "showzinho"; já chega querendo cesárea e quer "impor" suas vontades; é "pouco tolerante à dor" e quer um atendimento "mais individualizado" (demanda mais atenção, é "poliqueixosa").

"Aquelas que quando dá a dor nelas, a contração, ela diz que vai morrer. (...) já é a quinta vez que tá passando por isso e sabe que não vai morrer com aquela dor. Aí elas se tornam paciente difícil, porque ela não importa com o bebê dela, ela quer que passe a dor dela!" (Técnica em enfermagem 1).

Em ambos os casos são pacientes que não se submetem à obediência que lhes é esperada e à aceitação da dor do parto como algo natural, um preço a ser pago para ser mãe. Nessa situação, a maioria dos profissionais revelou utilizar uma conduta "mais ríspida", ameaças e "aumentar a voz" como formas de coagir a paciente a "colaborar". Essas ações, tidas como necessárias, são consideradas como legítimas no exercício da autoridade profissional pela maioria dos entrevistados:

“Ah, isso eu já falei também [Não grita se não eu não venho te atender! Se continuar eu paro agora o que eu estou fazendo!]. (...) Porque eu queria tentar chamar atenção pra ela colaborar no trabalho de parto. Eu jamais ia fazer isso porque eu nunca fiz isso, de largar a paciente sozinha na sala. Isso é uma... É uma forma de 'coação', uma forma de tentar 'dissuadir' a gestante... Dissuadir, não, né. Tentar fazer com que a gestante colabore mais. Porque eu já vi colegas largando mesmo, deixando ter nenê na cama, já vi em residência, já vi essas coisas, mas eu não tenho coragem de fazer isso, de largar. Mas eu já usei essa frase como uma forma de tentar 'chacoalhar' a pessoa, chamar a pessoa em atenção pra poder focar no objetivo, que é ganhar bebê." (Obstetra 6).

De acordo com vários entrevistados, ameaças de abandono são frequentes nas maternidades quando a paciente "não colabora" ou "faz escândalo”. E embora todos afirmem que não há uma intenção real de cumprir a ameaça, pode-se perceber na fala de alguns uma banalização do sofrimento da paciente e um uso corriqueiro deste recurso violento - a ameaça - percebido como legítimo ao exercício da autoridade.

Nesse sentido, a violência institucional, tal como a definimos, é reconhecida e admitida como prática comum por quase todos os entrevistados, ainda que a definição e nomeação do que seria violência institucional na visão destes profissionais tenha limites pouco claros. $\mathrm{O}$ termo "violência" é mais comumente associado à violência física na população em geral; e na área da saúde, a violência contra a mulher é frequentemente referida apenas à violência sexual e doméstica.

No cotidiano da prática dos entrevistados houve amplo reconhecimento de maus-tratos e desrespeitos, que em alguns momentos são percebidos e nomeados como violência e, em outros, como condutas necessárias ao trabalho; como parte do exercício da autoridade profissional. Dessa forma, gritar com a paciente pode ser considerado um desrespeito, um tratamento grosseiro, mas se a paciente é vista pelo profissional como "descontrolada" e precisa ser "chamada à razão", para a maioria dos entrevistados não constitui uma violência, mas apenas o exercício de sua autoridade profissional. A diferença de um momento para o outro parece depender da intensidade do ato, do contexto da situação, de um julgamento moral sobre a paciente e de quem é o profissional envolvido, no sentido de que foi mais recorrente nomearem como violência os atos dos outros profissionais do que os próprios.

Em contrapartida, os limites para o exercício da autoridade legítima 18 são reconhecidos na fala de um dos entrevistados que aponta o uso da força (ou de qualquer outro recurso violento) como algo que enfraquece ou anula a autoridade profissional: 
"O médico é uma autoridade, a enfermeira é uma autoridade, né, o policial, o motorista de ônibus (...) e assim por diante. E a autoridade, ela precisa ter uma postura (...). Inclusive, se ela não tem uma postura adequada é o caso de destituí-la de tal. Então entrar em briga não é uma postura de autoridade. Quando a autoridade acha que éo caso de usar a força, tem que usar a força pra acabar com aquilo e pronto, usar o mínimo possivel pra resolver aquela situação. Por isso que xingar, você tá entrando num bate-boca que aí você tá... Realmente você tá abdicando da autoridade, né?" (Obstetra 1).

O uso da violência na assistência à saúde como um recurso utilizado na relação profissional/ paciente revela o enfraquecimento das bases do poder e da autoridade médica: o consenso gerado baseando-se na comunicação e ação de sujeitos livres. Revela também a dificuldade de estabelecer uma comunicação livre com a mulher, considerando-a como um sujeito em situação de fragilidade e necessitando de cuidado.

A dificuldade para os entrevistados reconhecerem a violência no campo da assistência à saúde é revelada ainda na concepção de alguns de que a violência implicaria a maior gravidade do ato, causador de dano físico ou emocional propositalmente, humilhação intencional e preconceito. Entretanto, frases jocosas igualmente moralistas e preconceituosas frequentemente ditas em tom de "brincadeira" foram percebidas, por esses profissionais, apenas como uma forma de humor.

Assim, a maioria do que foi nomeado como desrespeito, observado em suas experiências profissionais, não foi identificado como um tipo de violência. Tal concepção acaba possibilitando que tais condutas sejam aceitas no cotidiano da assistência como toleráveis ou mesmo necessárias, e contribui para um processo de banalização da violência institucional.

De acordo com Sá 22, a banalização do mal e do sofrimento alheio nos serviços de saúde pode ser uma estratégia de defesa dos profissionais contra o próprio sofrimento, mas também, o resultado da banalização do mal numa sociedade que a autora define como estando entre a "impossibilidade da culpa" e a "falta de vergonha", fazendo com que a corrupção corroa cada vez mais os valores éticos fundamentais e acabe se tornando o que é esperado e até admirado, por meio de sua banalização.

No caso da assistência em maternidades, a banalização da violência institucional é travestida de boa prática profissional (seria para o bem da paciente) e exercício pretensamente legítimo de autoridade, já que a intenção é conseguir a "colaboração" da paciente. Lembramos que "co- laborar" implicaria uma relação dialógica com o outro: colaborar é trabalhar ("co-laborar") junto, ou nas palavras de Arendt 15: agir em concerto. O que se consegue com o uso da coação, da ameaça, do grito, da força ou de qualquer outro recurso violento, portanto, não é colaboração, mas submissão; é um fazer "sobre" alguém e não "com” alguém. Esse fato, no entanto, parece invisível ou pouco claro para os profissionais, sendo banalizado na prática cotidiana. São exemplos dessa banalização ameaçar, "falar mais ríspido" ou utilizar frases jocosas, algumas de conotação sexual, como forma de "brincar" com a paciente.

Pizzini 23 aponta para o uso de piadas e jargões humorísticos como forma de abordar determinados tabus sociais, como a relação entre sexo e nascimento. A autora considera ainda que o humor possa ser usado como forma de socialização em um meio de extrema hierarquização profissional, e que sirva também para alívio da tensão nos momentos mais críticos do processo de parto. Ela encontrou exemplos de desqualificação da dor, da autonomia e do saber sobre o próprio corpo das parturientes por intermédio do humor, sempre contendo algum elemento agressivo 23 .

Quase todos os nossos entrevistados relataram já terem utilizado ou presenciado o uso de frases como: "Na hora de fazer não chorou, está chorando agora por quê?", "na hora de fazer não chamou a mamãe, agora chama, né?”, “ah, não chora não, ano que vem você está aqui de novo", "se você ficar gritando o seu neném pode nascer surdo".

Embora muitos dos profissionais entrevistados reprovem esse tipo de "brincadeira" e a reconheçam como um tratamento grosseiro e desrespeitoso, os relatos apontam a banalização do seu uso, muito comum no cotidiano da assistência prestada às parturientes. Foi reconhecido ainda como desrespeito o tratamento grosseiro com imposição de valores ou julgamento moral, quebra de sigilo, invasão de privacidade, discriminação social ou étnica; tratar o outro como objeto (desrespeito à autonomia), negligência no atendimento (erro técnico, omitir ou não esclarecer informações importantes, abandono, desqualificar ou ignorar as queixas) e a ameaça ou represália de fato:

“Usar palavras que não condizem com o atendimento médico (...) frases assim: 'Na hora de fazer tava bom e agora fica dando trabalho' (...) já ouvi isso de boca de atendente, já ouvi isso de médico, de virar pra gestante e falar: 'É, na hora do bem bom você não reclamou, agora você tá reclamando, enchendo o saco.' Como: 'cala a boca', 'vou te deixar aqui sozinha' (...) Não é que seja uma 
coisa corriqueira, mas é uma coisa que é comum de ouvir" (Obstetra 6).

"Eu vou contar um caso pra você. 'Olha, minha filha, você tá muito gorda, viu!'. Você acha que isso é desrespeitoso? Muito, né. Ou então na hora que tá doendo, assim, na hora de nascer uma auxiliar fala assim: 'Pra fazer não doeu'. Você acha que é desrespeitoso? Você acha que isso é uma lenda? $\hat{E}$ uma rotina" (Obstetra 9).

Assim como em relação às pacientes, a maioria dos profissionais associou a violência institucional ao caráter pessoal de quem a pratica. Ser violento seria uma questão de "natureza rude", de índole, de "falha de caráter" ou uma questão de formação pessoal, falta de "berço", ou seja, em função do grupo social em que está inserido.

Esse tipo de justificativa naturaliza a violência, limita as possibilidades de questionamento crítico, contribuindo para a discriminação social da paciente, a banalização da violência institucional e sua maior invisibilização. E, não por acaso, alguns profissionais entrevistados tenderam a ser mais compassivos com a grosseria de seus colegas do que das pacientes, o que expressa a hierarquia de valores que regula as relações interpessoais entre profissionais, e destes com as pacientes.

Por outro lado, também foi apontado pelos profissionais como possíveis causas para a violência institucional um ritmo de trabalho alienante associado à precariedade de recursos, que resulta não só no esgotamento físico e emocional do profissional como na dificuldade de refletir sobre sua prática; a falta de comprometimento ético na formação profissional e a impunidade, sobretudo no serviço público, contra esses atos. Soma-se a essa impunidade a própria discriminação social contra a paciente atendida no serviço público:

"A discriminação do pobre é uma coisa muito forte, né. Eu acho que vem daí, quer dizer, o pobre é um estorvo, ele atrapalha e o serviço público gasta com pobre e eles não se (...), eles têm muitos filhos, né. Eu acho que tem isso por trás do sistema. (...) E tá sendo atendido de graça, né (...). Eu acho que esse pensamento ainda existe, mas é menos comum. (...) Tá sendo atendido de graça num hospital bom e ainda reclama, né" (Obstetra 1$)$.

"É porque é pobre, né. Porque no [hospital privado $\mathrm{X}$ ] ele não vai fazer isso, você entendeu? (...) Então eu acho que existe essa forma de ver as coisas. A paciente é pobre? Ah, tudo bem, né. Você percebe algumas situações, assim, que o profissional, seja médico ou enfermagem, né, ele não faria isso se tivesse num hospital 'top' de linha" (Obstetra 10).

Finalmente, cabe ressaltar que uma limitação deste estudo é que, por seu corte qualitativo, os dados não são generalizáveis para o conjunto dos profissionais, ou mesmo para as maternidades públicas, embora os dados apresentados estejam em consonância com a literatura a respeito.

\section{Considerações finais}

Condutas violentas como o uso de jargões pejorativos, ameaças e reprimendas contra as pacientes no cotidiano da assistência em maternidades e negligência no manejo da dor são consideradas comuns e até consensuais entre os profissionais, que por vezes as confundem com o exercício da autoridade em um contexto "difícil”. Essas ações são forjadas por relações de gênero que sistematicamente (e historicamente) obstruem a comunicação e ação livres, interditam a sexualidade e desrespeitam os direitos da paciente.

No que se refere à banalização do sofrimento alheio, Sá 22 chama a atenção para uma "crise social” que é revelada pela degradação dos valores sociais e do cuidado com o outro. O mal produzido nos serviços de saúde, portanto, seria um reflexo do mal produzido e agravado na própria sociedade e igualmente banalizado.

Concordando com a autora, mas considerando que nem as práticas dos profissionais de saúde são apenas decorrentes das condições sociais do trabalho e nem as práticas de saúde apenas são reflexo (direto ou mecânico) das práticas sociais, diremos que as práticas de saúde reproduzem em seu interior os valores da sociedade de modo novo: o mal produzido nos serviços de saúde, sem realizar-se do ponto de vista concreto do mesmo modo que o mal social guarda relação com este, (re)produzindo-o. Com isso queremos dizer que ao ser prática social, a de saúde orienta-se na mesma direção banalizadora e naturalizadora das violências, mas, de modo original, cria em seu interior, isto é, seus agentes profissionais é que criam aceitações da violência que se transformam em atos "necessários ao cuidado" e, assim, 'boas práticas' assistenciais. Deslocam, pois, o aspecto ético-moral de seus atos violentos para qualificá-los como uma exigência da técnica, como se fosse parte do domínio técnico-científico das práticas dos profissionais.

Mas compreender os atos violentos como apenas repetição da sua banalização social e não levar em conta a inovação neste deslocamento da questão oculta a participação dos profissionais como sujeitos e agentes dessa outra formulação da banalização da violência, com o que os profissionais e a medicina participam dos valores e da construção dos ordenamentos sociais vigentes. Segundo Schraiber 19, tomaremos 
as práticas de assistência à saúde e as práticas profissionais como parte das práticas sociais. Mas ser parte de um todo significa ao mesmo tempo repetir e inovar este todo, pois, tal como a autora concebe a medicina ao reproduzir-se como prática social, altera aspectos deste mesmo social, em razão de suas próprias peculiaridades internas (de prática técnico-cientifica). No cenário das maternidades públicas apontado pelos entrevistados, no qual conflitam diferentes interesses - dos gestores (por meio da instituição), dos profissionais e das pacientes - a qualidade da interação nas relações é enfraquecida diante da precariedade de recursos, da excessiva demanda por uma rapidez na produção de serviço e de uma segurança, cada vez mais, depositada no uso de recursos tecnológicos como mediadores desta relação e como solução para estes conflitos. Como apontado por Schraiber 19, o ideal de uma boa assistência deixa de ser pautado na qualidade ética da interação entre profissionais e pacientes e na confiança resultante desta interação para se basear no maior acesso à tecnologia, que representa um bem em si. No caso da assistência a um episódio geralmente fisiológico, como o parto, fica mais evidente a impossibilidade de substituição da ética das relações pelo acesso à tecnologia, já que o fim do cuidado como valor maior abre espaço para o exercício da violência e coloca em risco, além da saúde das mulheres e crianças, a própria prática médica. Outra questão a se considerar, também apontada por Schraiber 19, é a preocupação maior dos profissionais com seu próprio desempenho, desde o acerto diagnóstico ao uso correto das tecnologias materiais, do que a preocupação com a colaboração da paciente como uma forma de somar o outro em seu desempenho de médico. Ao contrário, como os presentes resultados apontam o sentido dado pelos profissionais à noção de "colaboração" por parte das pacientes é o de sua negação, isto é, colaborariam as que abdicam de se expressar, transformadas em corpos dóceis e submissos à intervenção unilateral. Para as demandas da própria paciente, como seria o caso da analgesia de parto, ou da maior participação e conhecimento das intervenções, como o monitoramento do desenvolvimento da dilatação uterina, ou da presença de acompanhantes, não há intervenção oferecida, e por vezes estas demandas, além de silenciadas, sofrem represálias 21 .

As diversas iniciativas relacionadas à humanização do parto são um elemento que aponta para uma reação propondo mudanças nesta situação atual. Congregando mulheres e alguns profissionais, as iniciativas governamentais e da sociedade civil em direção à construção de casas de parto, da atuação de parteiras e doulas, e do parto domiciliar são ao mesmo tempo uma forte crítica à medicina e um convite à possibilidade da reinvenção social do cuidado às gestantes e puérperas. A proposta do uso mais comedido e apropriado de tecnologias e melhor qualidade ética na relação são geradas a partir da crise da confiança aqui retratada. Busca-se, assim, restaurar a autonomia das mulheres, o controle sobre seu corpo e seus processos, e a qualidade ética e técnica nas relações estabelecidas entre gestantes e profissionais. 


\section{Resumen}

El presente artículo versa sobre la violencia institucional en maternidades, según la óptica de profesionales de salud, en base a los datos de una investigación sobre este tema en la ciudad de Sao Paulo, Brasil. Para ello, fueron entrevistados 18 profesionales de salud activos en la red pública y privada, entre los que se encontraban médicos obstetras, enfermeras y técnicos en enfermería. Se utilizó un cuestionario semiestructurado con items sobre la experiencia profesional y el concepto de violencia. El análisis reveló el reconocimiento - por parte de esos profesionales- de prácticas discriminatorias e irrespetuosas en el día a día de la asistencia a mujeres embarazadas, parturientas y puérperas. Se citan como ejemplos de esas prácticas el uso de apelativos peyorativos como una forma de humor, amenazas, reprimendas y negligencia en el manejo del dolor. Esas prácticas no son generalmente percibidas por los profesionales como violentas, sino como un ejercicio de autoridad en un contexto considerado "difícil". Este contexto revela la banalización de la violencia institucional que disfrazada de buena práctica, ya que se produce por el bien del paciente, acaba siendo invisibilizada en la cotidianidad de la asistencia.

Violencia Contra la Mujeres; Servicios de Salud Materna; Mujeres

\section{Colaboradores}

J. M. Aguiar participou da concepção do projeto, análise dos dados, elaboração do manuscrito e aprovou a versão final do artigo. A. F. P. L. d'Oliveira colaborou na análise dos dados, revisão crítica do manuscrito e aprovação da versão final do artigo. L. B. Schraiber colaborou na revisão crítica do manuscrito e aprovação da versão final do artigo.

\section{Agradecimentos}

Agradecimento à FAPESP pela bolsa de doutorado que possibilitou esta pesquisa.

\section{Referências}

1. Menezes DCS, Leite IC, Schramm JMA, Leal MC. Avaliação da peregrinação anteparto numa amostra de puérperas no Município do Rio de Janeiro, Brasil, 1999/2001. Cad Saúde Pública 2006; 22:553-9.

2. Richard F, Filali H, Lardi M, De Brouwere V. Accouchement à l'hôpital au Maroc ou comment concilier des logiques différentes. Rev Épidémiol Santé Publique 2003; 51:39-54.

3. Nogueira MI. Assistência pré-natal: prática de saúde a serviço da vida. São Paulo: Editora Hucitec; 1994.

4. Dalsgaard AL. Vida e esperanças: esterilização feminina no Nordeste. São Paulo: Editora Unesp; 2006.

5. McCallum C, Reis AP. Re-significando a dor e superando a solidão: experiências do parto entre adolescentes de classes populares atendidas em uma maternidade pública de Salvador, Bahia, Brasil. Cad Saúde Pública 2006; 22:1483-91.

6. Chiarotti S, Jurado MG, Aucia A, Arminchiardi S. Con todo al aire. Reporte de derechos humanos sobre atención en salud reproductiva en hospitales públicos. Rosario: Instituto de Género, Derecho y Desarrollo/Buenos Aires: Comité de América Latina y el Caribe para la Defensa de los Derechos de la Mujer; 2003.
7. Hotimsky SN, Rattner D, Venancio SI, Bógus CM, Miranda MM. O parto como eu vejo... ou como eu o desejo? Expectativas de gestantes, usuárias do SUS, acerca do parto e da assistência obstétrica. Cad Saúde Pública 2002; 18:1303-11.

8. d'Oliveira AFPL, Diniz SG, Schraiber LB. Violence against women in health-care institutions: an emerging problem. Lancet 2002; 359:1681-5.

9. Comité de América Latina y el Caribe para la Defensa de los Derechos de la Mujer; Centro Legal para Derechos Reproductivos y Políticas Públicas. Silencio y complicidad. Violencia contra las mujeres en los servicios públicos de salud en el Perú. Lima: Comité de América Latina y el Caribe para la Defensa de los Derechos de la Mujer/Centro Legal para Derechos Reproductivos y Políticas Públicas; 1998.

10. Scott J. Gênero: uma categoria útil para análise histórica. Corpo, Educação e Realidade (Porto Alegre) 1990; 16:1-27.

11. Ministério da Saúde. Portaria no 569, de 1 de junho de 2000. Institui o Programa de Humanização no Pré-Natal e Nascimento, no âmbito do Sistema Único de Saúde. Diário Oficial da União 2000; 8 jun. 
12. Diniz CSG. Humanização da assistência ao parto no Brasil: os muitos sentidos de um movimento. Ciênc Saúde Coletiva 2005; 10:627-37.

13. Deslandes SF. Análise do discurso oficial sobre a humanização da assistência hospitalar. Ciênc Saúde Coletiva 2004; 9:7-14.

14. Chauí M. Participando do debate sobre mulher e violência. In: Chauí M, Cardoso R, Paoli MC, organizadores. Perspectivas Antropológicas da Mulher. Rio de Janeiro: Jorge Zahar Editores; 1985. p. 25-62.

15. Arendt H. Sobre a violência. Rio de Janeiro: Civilização Brasileira; 2009.

16. Foucault M. O sujeito e o poder. In: Rabinow P, Dreyfus HL, Foucault M, organizadores. Uma trajetória filosófica para além do estruturalismo e da hermenêutica. Rio de Janeiro: Forense Universitária; 1995. p. 231-49.

17. Schraiber LB. Acción técnica y acción moral: el doble carácter de la prática de los profesionales de la salud. Apuntes para el debate. In: Castro R, Gómez AL, editores. Poder médico y ciudadanía: el conflicto social de los profesionales de la salud con los derechos reproductivos en América Latina. Montevideo: Universidad de la República; 2010. p. 11-26.

18. Starr P. Orígenes sociales de la soberanía profesional. In: Starr P, editor. La transformación social de la medicina en los Estados Unidos de América. México DF: Biblioteca de la Salud/Secretaría de Salud/Fondo de Cultura Económica; 1991. p. 17-44.
19. Schraiber LB. O médico e suas interações: a crise dos vínculos de confiança. São Paulo: Editora Hucitec; 2008.

20. Teixeira NZF, Pereira WR. Parto hospitalar - experiências de mulheres da periferia de Cuiabá-MT. Rev Bras Enferm 2006; 59:740-4.

21. Aguiar JM, d'Oliveira AFPL. Violência institucional em maternidades públicas sob a ótica das usuárias. Interface Comun Saúde Educ 2011; 15:79-92.

22. Sá MC. Em busca de uma porta de saída: os destinos da solidariedade, da cooperação e do cuidado com a vida na porta de entrada de um hospital de emergência [Tese de Doutorado]. São Paulo: Instituto de Psicologia, Universidade de São Paulo; 2005.

23. Pizzini F. Communication hierarchies in humour: gender differences in the obstetrical/gynaecological setting. Discourse \& Society 1991; 2:477-88.

Recebido em 25/Mai/2012

Versão final reapresentada em 20/Dez/2012

Aprovado em 12/Jun/2013 